\title{
Original
}

\section{Poor mother-offspring relationships in rats with Cacna1a mutation}

\author{
Nozomi KAWAKAMI ${ }^{1)}$, Kiyoka KOBAYASHI ${ }^{1)}$, Ayumu NISHIMURA ${ }^{2)}$ and Iori OHMORI ${ }^{1,3,4)}$ \\ 1) Department of Physiology, Graduate School of Medicine, Dentistry and Pharmaceutical Sciences, Okayama University, 5-1 \\ Shikatacho 2-chome, Kita-ku, Okayama 700-8558, Japan \\ 2) Okayama University, 5-1 Shikatacho 2-chome, Kita-ku, Okayama 700-8558, Japan \\ ${ }^{3)}$ Graduate School of Education, Okayama University, 5-1 Shikatacho 2-chome, Kita-ku, Okayama 700-8558, Japan \\ 4) Department of Child Neurology, Graduate School of Medicine, Dentistry and Pharmaceutical Sciences, Okayama University, \\ 1-1 Tsushimanaka 3-chome, Kita-ku, Okayama 700-8558, Japan
}

\begin{abstract}
Homozygous Groggy dams, which carry a Cacna1a missense mutation, often show no interest in their offspring, leading to frequent offspring deaths due to lack of nurturing. The present study aimed to clarify whether the Cacna1a mutation contributes to impaired attachment behaviors between dam and offspring. The open field test showed that homozygous female rats exhibited markedly short travel distance, whereas no difference was found between the motor activity of heterozygous females and that of wild types (WT). A series of behavioral tests was performed to compare the mother-offspring relationship between WT and heterozygous rats. Performance in the pup retrieval test was significantly less successful in heterozygous than WT dams. During the experiment, heterozygous dams spent significantly less time licking and crouching than WT dams. The offspring dam-seeking behavior test revealed that heterozygous pups' vocalizations were significantly less frequent and shorter than those of WT pups. Although no significant difference was found between WT and heterozygous offspring in the olfactory sense test, using a piece of chocolate, heterozygous pups took significantly longer to reach a sample of the dam's bedding. Taken together, these findings suggest that the Cacna1a mutation impairs both the dam's maternal behavior and the offspring's attachment behavior toward the dam.
\end{abstract}

Key words: attachment, Cacna1a, calcium channel, mother-offspring relationship, rat model

\section{Introduction}

Voltage-gated calcium channels (VGCC) are a family of transmembrane proteins involved in calcium homeostasis, gene expression, and neurotransmitter release. Multiple types of VGCCs have been described, both in the central nervous system and in the muscles and secretory cells. Presynaptic $\mathrm{Ca}^{2+}$ entry occurs through VGCC activated by membrane depolarization, after which $\mathrm{Ca}^{2+}$ elevation triggers neurotransmitter release from synaptic vesicles. $\mathrm{P} / \mathrm{Q}$ type $\mathrm{Ca}$ channels $\left(\mathrm{Ca}_{\mathrm{v}} 2.1\right)$ are highly expressed at the presynaptic membranes, specifically in cerebellar Purkinje cells, and play an important role in neurotransmitter release $[12,15]$.

In mice, both selective $\mathrm{Ca}_{\mathrm{v}} 2.1-\mathrm{knockout}\left(\mathrm{Ca}_{\mathrm{v}} 2.1 \mathrm{KO}\right)$ and missense mutations cause cerebellar atrophy, loss of righting reflex, ataxia, and absence epilepsy [27]. In humans, the CACNA1A is a causative gene of neurological disorders, such as familial hemiplegic migraine type 1 , episodic ataxia type 2, spinocerebellar ataxia type 6 , absence epilepsy, intellecyual deficiency, executive dysfunction, attention-deficit/hyperactivity disorder, and autism $[9,12,23]$.

Homozygous Groggy (GRY) rats with the CacnalaM251K mutation exhibit symptoms of ataxia and absence epilepsy [42]. Electrophysiological studies, using

(Received 9 July 2019 / Accepted 22 October 2019 / Published online in J-STAGE 13 November 2019)

Corresponding author: I. Ohmori.e-mail: iori@md.okayama-u.ac.jp

c. $(\$$ This is an open-access article distributed under the terms of the Creative Commons Attribution Non-Commercial No Derivatives BY NC ND (by-nc-nd) License <http://creativecommons.org/licenses/by-nc-nd/4.0/>.

(C)2020 Japanese Association for Laboratory Animal Science 
the patch clamp technique in cerebellar Purkinje cells acutely isolated from homozygous GRY rats, showed increased current density and a depolarization shift in voltage-gated activation. Such electrophysiological changes may contribute to neurological symptoms [39]. When rearing GRY rats we noticed that, after delivery, most homozygous GRY dams showed no interest in their offspring, leading them to die due to lack of nurturing. The homozygous GRY dam did not keep the bodies of the surviving offspring clean in a home cage. Although homozygous GRY rats exhibit ataxic gait, they show no impairment in drinking, eating, or mating, and there is no difference in life-span. Ataxic gait is unlikely to constitute a cause for maternal behavior impairment in the homozygous GRY dam. Therefore, the present study investigated the effect of Cacnala mutation on the mother-offspring relationship using heterozygous rats with no motor deficits.

\section{Materials and Methods}

\section{Animals}

GRY rats [38] with an M251K-Cacnala mutation were obtained from the National Bio Resource Project for the Rat in Japan, Kyoto University. The M251K missense mutation involves a replacement of adenine with thymine at the 752nd nucleotide of the Cacnala gene, altering the $251 \mathrm{st}$ amino acid methionine (ATG) to lysine (AAG). This mutation is located in the pore-forming region through which calcium ions pass.

Genomic DNA was extracted from the rats' tail for genotype confirmation. The $\mathrm{M} 251 \mathrm{~K}$ region for each rat was then amplified by PCR using the extracted DNA as template. The primers used were: 5'-TCTCTGTCTCCCCAGGTTTAC-3' (Forward) and 5'-GTGGCTAACACACAGCTTTGC-3' (Reverse). PCR products, including $\mathrm{M} 251 \mathrm{~K}$, were digested with the restriction enzyme PsiI, and the genotype was identified using PCR restriction fragment length polymorphism (RFLP). Thus, the TTTTATAAG sequence of the mutant allele was digested with PsiI, whereas the TTTTATATG sequence of the WT allele was not.

The animals were kept and bred at the Institute of Laboratory of Animals, Graduate School of Medicine, Okayama University in air-conditioned rooms $\left(24 \pm 2{ }^{\circ} \mathrm{C}\right)$ under a 12-h light/dark cycle and food and water ad libitum. All experiments were performed according to protocols approved by the Institutional Animal Care and Use Committee of Okayama University.

\section{Survival rate of pups}

In order to evaluate the dams' parenting ability, the average number of pups born and their survival rate (number of raised pups/number of pups born) were observed for 2 weeks during the lactation period. Maternal genotypes were either WT, heterozygous or homozygous. To minimize the influence of offspring genetic factors on parenting behavior, mating was planned so that the offspring genotypes were either heterozygous or WT.

\section{Open field test}

In behavioral tests, reduced motor activity may lead to underestimated results. Therefore, the activity levels of WT, heterozygous, and homozygous female rats were evaluated at six weeks of age. The open field $(70 \times 70 \times$ $40 \mathrm{~cm}$ ) was used to measure the rats' moving distance over $10 \mathrm{~min}$. The floor was sectioned into 16 squares, among which the four central ones were designated as the central zone and the 12 surrounding the center were designated as the peripheral zone. Behavioral tests were recorded using a video camera and analyzed using the behavior analysis software ANY-maze (Stoelting Co., Wood Dale, IL, USA).

\section{Evaluation of maternal behavior}

A. Nesting behavior: Nesting is a maternal behavior that ensures the safety of both dams and offspring and maintains the offspring's body temperature. This behavior is also observed in adults aged over 40 days for sleeping and temperature regulation $[3,6,19]$.

The previously reported methods were modified [3, 6]. Nesting was observed both in WT and heterozygous nulliparous females at 7-8 weeks of age. Cotton fiber nestlets were used as nesting material (Ancare Co., Bellmore, NY, USA) by placing nine nestlet blocks, of $5 \times$ $5 \mathrm{~cm}$ each, in the cage $(38 \times 22 \times 20 \mathrm{~cm})$. After five days, nestlet blocks with more than $3 / 4$ remaining were weighed.

B. Pup Retrieval behavior: Nursing female rats usually collect all offspring into the nest to keep them warm and to feed them. In order to facilitate nursing, dams adopt a nursing posture, arching the back and covering the pups, while licking them to keep their bodies clean and stimulate metabolism. Until postnatal day 14, separating the pups from the dam leads the dam to repeatedly retrieve them into the nest $[5,8,31]$, and this behavior is frequently used to evaluate parenting ability.

In the present study, retrieval behavior was assessed on postnatal day eight by temporarily removing all offspring from the home cage and keeping them separated from the dam for five minutes. After five minutes, three pups were placed back into the home cage at the opposite end of the nest (Fig. 2C). Retrieval behavior was then recorded for $15 \mathrm{~min}$ with a video camera. The success 
rate of retrieving all three offspring back to the nest, the total number of pups retrieved and the duration of licking and crouching were measured over $15 \mathrm{~min}$. To minimize the influence of offspring factors on the dam's retrieval behavior, heterozygous offspring were used for WT dams and WT or heterozygous offspring were used for heterozygous dams.

\section{Offspring's attachment behavior toward the dam}

A. Ultrasonic vocalization (USV): When out of the nest or separated from the dam, rat pups will vocalize, stimulating maternal retrieval behavior. Vocalization is also known to constitute a signal for the dams to express fostering behavior for the premature offspring [43]. In the present study, the offspring's attachment toward the dam was evaluated by measuring pups' USVs [7]. To avoid the influence of maternal factors on offspring vocalizations, WT dams were used for both WT and heterozygous offspring. The assessment was performed on postnatal day 9 .

When isolated from the nest or the dam, rat pups vocalize in the ultrasonic range of 50 to $80 \mathrm{kHz}$. The dam recognizes this USVand retrieves the offspring back into the nest. Retrieval behavior is thought to reinforce the offspring's vocalization and to increase the number of USVs upon new separations [33].

Ultra Vox (Noldus Information Technology, Wageningen, Netherlands) was used to record the number and duration of vocalizations longer than $0.03 \mathrm{~s}$, at a frequency of $50 \mathrm{kHz}$ for $5 \mathrm{~min}$. The total process took 15 min, comprising three 5-minutes periods (Fig. 3A). One pup was isolated from the home cage containing the dam and siblings, and 50-kHz USVs were measured for five minutes (Isolation 1). For the following five minutes, the pup was returned to the home cage. In the last five- minutes period, the pup was removed once more and $50 \mathrm{-kHz}$ USVs was measured for five minutes (Isolation 2).

B. Olfactory preference test: The olfactory preference test was used to evaluate whether olfactory cues trigger exploratory behavior in the offspring [40]. The behavior of WT and heterozygous offspring was compared.

The previously reported methods were modified [21, 40]. A sample of the dam's used bedding and a sample of new bedding were each laid at either end of the test cage $(8.5 \times 8 \times 13 \mathrm{~cm})$. A ten-day old pup was placed at the center of the cage, and the time that it took to touch the wall of their dam's bedding with the nose was recorded (Fig. 4A). The maximum measuring time was set as five minutes, after which the trial was considered as a failure.

C. Food localization test: The food localization test was performed to screen for olfactory system abnor- malities [21, 45]. The olfaction of WT and heterozygotes was evaluated from 4 to 6 weeks of age. Prior to evaluation, rats were fasted overnight for $16 \mathrm{~h}$. The time that it took for the rat to find a small piece of chocolate buried under new bedding $(\sim 2.5 \mathrm{~cm})$ at the middle of the cage $(8.5 \times 8 \times 13 \mathrm{~cm})$ was recorded.

\section{Statistical analysis}

Results are presented as mean $\pm \mathrm{SE}$. The success rate of retrieval behavior and olfactory preference test were analyzed using the chi-square test. The $t$-test was used for all other experiments. A level of $P<0.05$ was considered statistically significant.

\section{Results}

\section{Survival rate of pups}

Figure 1A shows the average number of pups born in each pregnancy. The average number of births (P 0$)$ was $10.4 \pm 0.4$ for WT dams ( $\mathrm{n}=19)$ and WT offspring, 10.3 \pm 0.8 for WT dams $(\mathrm{n}=5)$ and heterozygous offspring, $9.1 \pm 0.6$ for heterozygous dams $(n=7)$ and WT or heterozygous offspring, and $7.8 \pm 0.5$ for homozygous dams $(n=8)$ and heterozygous offspring. The average number of pups born and their survival rate were significantly lower in homozygous dams with heterozygous pups than WT dams with heterozygous pups $(* * * P<0.001)$ (Figs. $1 \mathrm{~A}$ and $\mathrm{B}$, respectively).

\section{Open field Test}

Figures $1 \mathrm{C}$ and D show the distance traveled in the open field and the time spent in each zone. The total distance traveled over $10 \mathrm{~min}$ was $35.7 \pm 3.0 \mathrm{~m}$ for WT female rats $(n=8), 34.3 \pm 0.6 \mathrm{~m}$ for heterozygotes $(n=10)$, and $0.86 \pm 0.4 \mathrm{~m}$ for homozygotes $(\mathrm{n}=4)$. The homozygous female rats exhibited significantly reduced total distance compared to WT rats $(* * * P<0.001)$. No significant difference was observed between WT and heterozygotes regarding the total distance traveled and time spent in each zone. Since the motor capacity of homozygous females was significantly lower than that of WT and heterozygotes, subsequent behavioral tests were performed only in WT and heterozygotes.

\section{Evaluation of maternal behavior}

A. Nesting behavior: The use of nestlet blocks was observed over five days. Both WT and heterozygotes stacked the shredded blocks high with a hollow in center area (Fig. 2A). No difference was observed between WT and heterozygotes regarding the shape of the nest. On day 5 , the weight of non-shredded nestlets was measured, revealing no significant differences between the blocks 


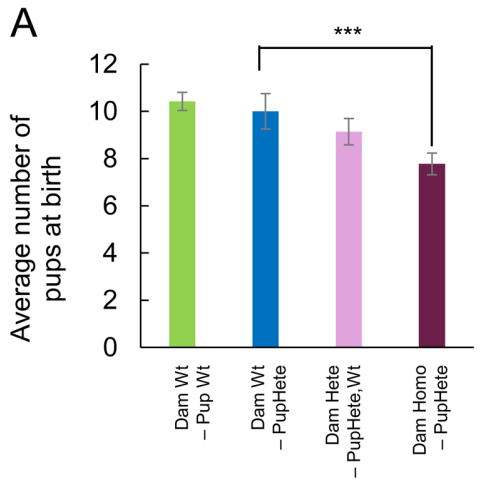

C

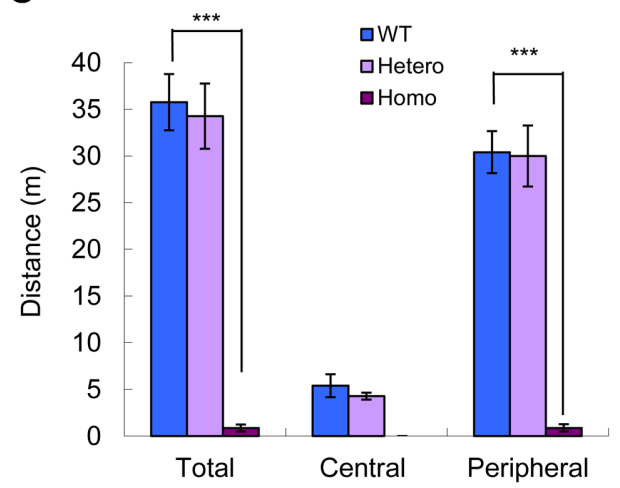

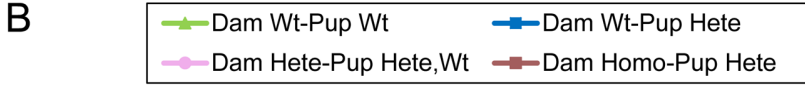

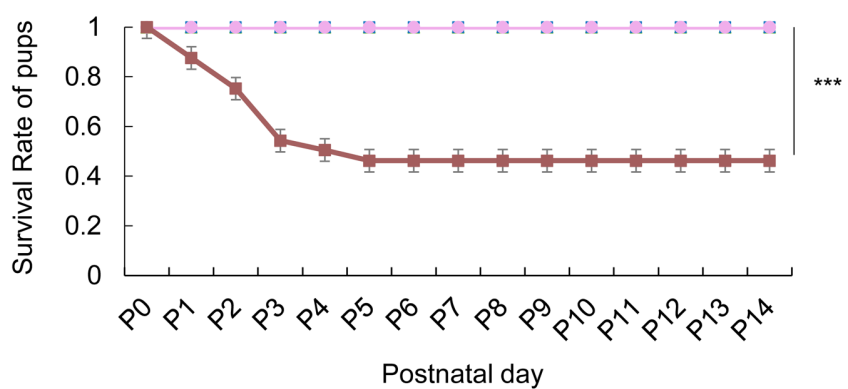

D

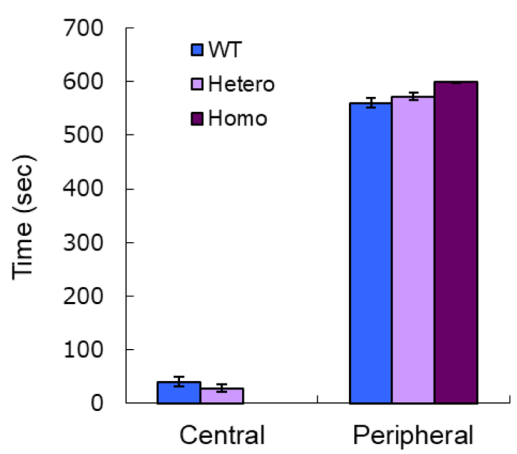

Fig. 1. Survival rate of pups and performance in the open field. The average number of pups at birth (A) and survival rate of pups (B) showed significant differences between wild types (WT) dams with heterozygous pups and homozygous dams with heterozygous pups (B) $(* * * P<0.001)$. The total distance traveled (C) and time spent in each zone (D) of the open field are shown. The total and peripheral distances were markedly lower in homozygous female rats as compared with WT $(* * * P<0.001)$, but there was no significant difference between WT and the heterozygotes.

used by WT $(9.9 \pm 1.3 \mathrm{~g}, \mathrm{n}=12)$ and heterozygotes $(10.8$ $\pm 1.8 \mathrm{~g}, \mathrm{n}=10$ ) (Fig. 2B).

B. Pup retrieval behavior: The success rate for retrieving the three pups into the nest within 15 min was $40 \%$ (6 out of 15 trials) for WT dams, whereas no heterozygous dam succeeded in all 14 trials. The retrieval success rate was significantly lower in heterozygous dams (Fig. 2D) $(* * P<0.01)$. The total number of pups retrieved was $2.07 \pm 0.3$ for WT and $0.071 \pm 0.07$ for heterozygotes $(* * * P<0.001)$ (Fig. 2E). Compared to WT, most heterozygous dams failed to retrieve even one pup. The licking duration was $69.2 \pm 10.8 \mathrm{~s}$ for WT and $22.4 \pm 8.7 \mathrm{~s}$ for heterozygotes $(* * P<0.01)$ (Fig. $2 \mathrm{~F})$, and the crouching duration was $174.0 \pm 62.3 \mathrm{~s}$ for WT and $16.3 \pm 6.8 \mathrm{~s}$ for heterozygotes ( $* P=0.03$ ) (Fig. $2 \mathrm{G}$ ). Heterozygous dams exhibited licking and the nursing posture significantly less than WT dams.

\section{Offspring's attachment behavior toward the dam}

A: Ultrasonic vocalization (USV): Figure 3B shows representative patterns of USV in WT and heterozygous offspring. For Isolation 1, the number of vocalizations in five minutes was $259.0 \pm 27.6$ for WT and $69.8 \pm 11.9$ for heterozygous offspring $(* * * P<0.001)$ (Fig. 3C). For Isolation 2, WT pups vocalized $464.8 \pm 33.7$ times, whereas heterozygotes vocalized $152.9 \pm 20.9$ times $(P<0.001)$ (Fig. 3C). Both for Isolation 1 and 2, the number of vocalizations was significantly lower in heterozygotes than WT pups. For Isolation 1, the duration per vocalization ( 1 event) was $0.071 \pm 0.0021 \mathrm{~s}$ for $\mathrm{WT}$ and $0.060 \pm 0.0022 \mathrm{~s}$ for heterozygotes $(* * P<0.01)$. For Isolation 2, the duration was $0.079 \pm 0.0023 \mathrm{~s}$ in WT and $0.064 \pm 0.0023 \mathrm{~s}$ in heterozygotes $(* * P<0.01)$ (Fig. 3D). For both Isolation 1 and 2, heterozygotes had significantly shorter vocalizations than WT.

B. Olfactory preference test: Within five minutes, $96.0 \%$ (24 out of 25 ) of WT and $87.1 \%$ (27 out of 31 ) of heterozygous offspring reached the dam's bedding (Fig. 4B). In average, WT pups $(n=25)$ took $38.4 \pm 4.0$ $\mathrm{s}$ to move to the dam's bedding, whereas heterozygotes $(n=31)$ took $79.4 \pm 11.8 \mathrm{~s}$. Heterozygotes took significantly longer time than WT $(* P=0.016)$ (Fig. $4 \mathrm{C})$.

C. Food localization test: No significant difference was observed between WT $(72.6 \pm 7.4 \mathrm{~s}, \mathrm{n}=22)$ and heterozygous offspring $(74.2 \pm 13.2 \mathrm{~s}, \mathrm{n}=17)$ regarding the time taken to find a piece of chocolate $(P=0.89)$ (Fig. 4D). 
A

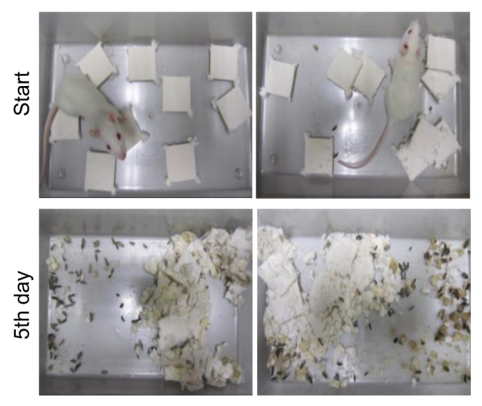

B

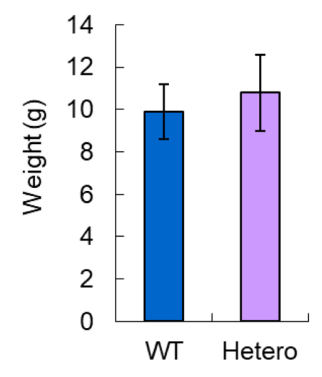

C

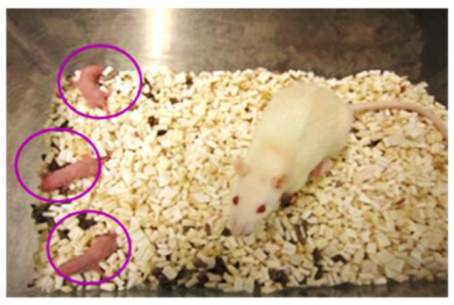

D

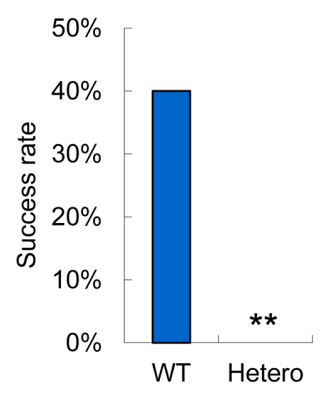

E

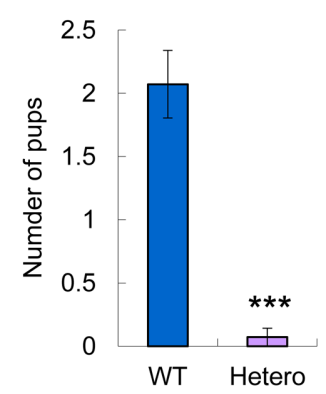

$\mathrm{F}$

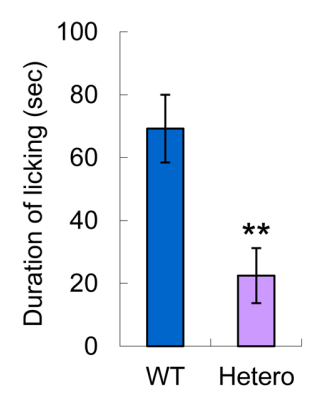

G

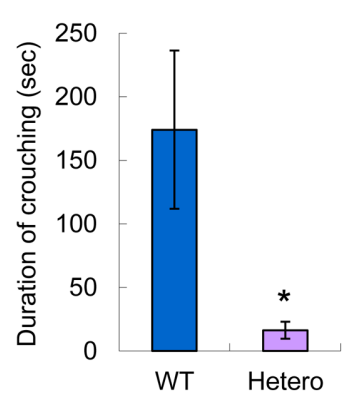

Fig. 2. Maternal behavior tests. Representative pictures of nestlets used by wild types (WT) and heterozygotes at the start of the measurement (upper row) and the fifth day (lower row) (A). There was no significant difference between WT and heterozygous dams in terms of nesting behavior (B). Experimental setup of the pup retrieval test (C). The rate of success for retrieval of three offspring (D) and the total number of pups retrieved (E) were significantly lower in heterozygous than WT dams. The time spent by dams licking (F) and crouching over the pups $(\mathrm{G})$ was significantly shorter in heterozygous than WT dams (WT dam: $\mathrm{n}=4$, heterozygous offspring: $\mathrm{n}=45$, heterozygous dam: $\mathrm{n}=4$ heterozygous or WT offspring: $\mathrm{n}=42,{ }^{*} P<0.05, * * P<0.01,{ }^{* * *} P<0.001$ ).

\section{Discussion}

The number of pups born was significantly lower in homozygous GRY rats than in WT. Smaller litter size is associated with reproductive hormone disorder in homozygous GRY dams or pup-killing before the number of pups was counted. Further examination of reproductive hormones is necessary to clarify these possibilities. Ultrasonic echo be performed to determine the number of pups during pregnancy. The present study revealed that heterozygous dams with no motor deficits show impaired pup retrieval behavior and shorter duration of licking and crouching than WT dams. Moreover, heterozygous offspring display fewer vocalizations to call a WT dam and lower preference by a WT dam's bedding. These findings suggest that Cacnala mutation may contribute for a tenuous dam-offspring relationship. In humans, CACNA1A mutations have been linked to neuropsychiatric disorders such as absence epilepsy, intellectual disability, familial hemiplegic migraine type 1 , episodic ataxia type 2 , spinocerebellar ataxia type 6 , and autism $[9,27]$. Although homozygous GRY rats are known to exhibit cerebellar ataxia and absence epilepsy, heterozygous rats do not present with these phenotypes [39,
42]. This study revealed that heterozygous GRY rats had impaired maternal behavior.

Possible causes of parenting failure in GRY dams may involve dysfunctions caused by certain brain lesions, or dysfunctional release of certain neurotransmitters. $\mathrm{Ca}_{\mathrm{v}} 2.1$ channel coded by the CACNA1A gene regulate synaptic transmission in the neuronal cells of the thalamus, cerebellum, hippocampus, and frontal cortex [9]. Absence epilepsy, one of the disorders associated with CACANA1A mutations, involves abnormal interactions in the corticothalamic pathways $[16,30]$. Human studies of parent-infant relationships based on functional magnetic resonance imaging (fMRI) revealed that, in healthy participants, the thalamus, cortex, midbrain, hypothalamus, striatum, and septal regions are activated when a baby cries $[17,25,36]$. The mother's brain regions that are activated by the infant's cue partially overlap with the brain regions where $\mathrm{Ca}_{\mathrm{v}} 2.1$ channels express.

Hormones associated with late pregnancy and birth, such as progesterone, estrogen, prolactin, and oxytocin, act in the medial preoptic area to make pup stimuli salient to the new mother [2]. In nursing dams, pup suckling promotes the secretion of the maternal neuronal hormone oxytocin $[24,32,41]$. The role of oxytocin has 

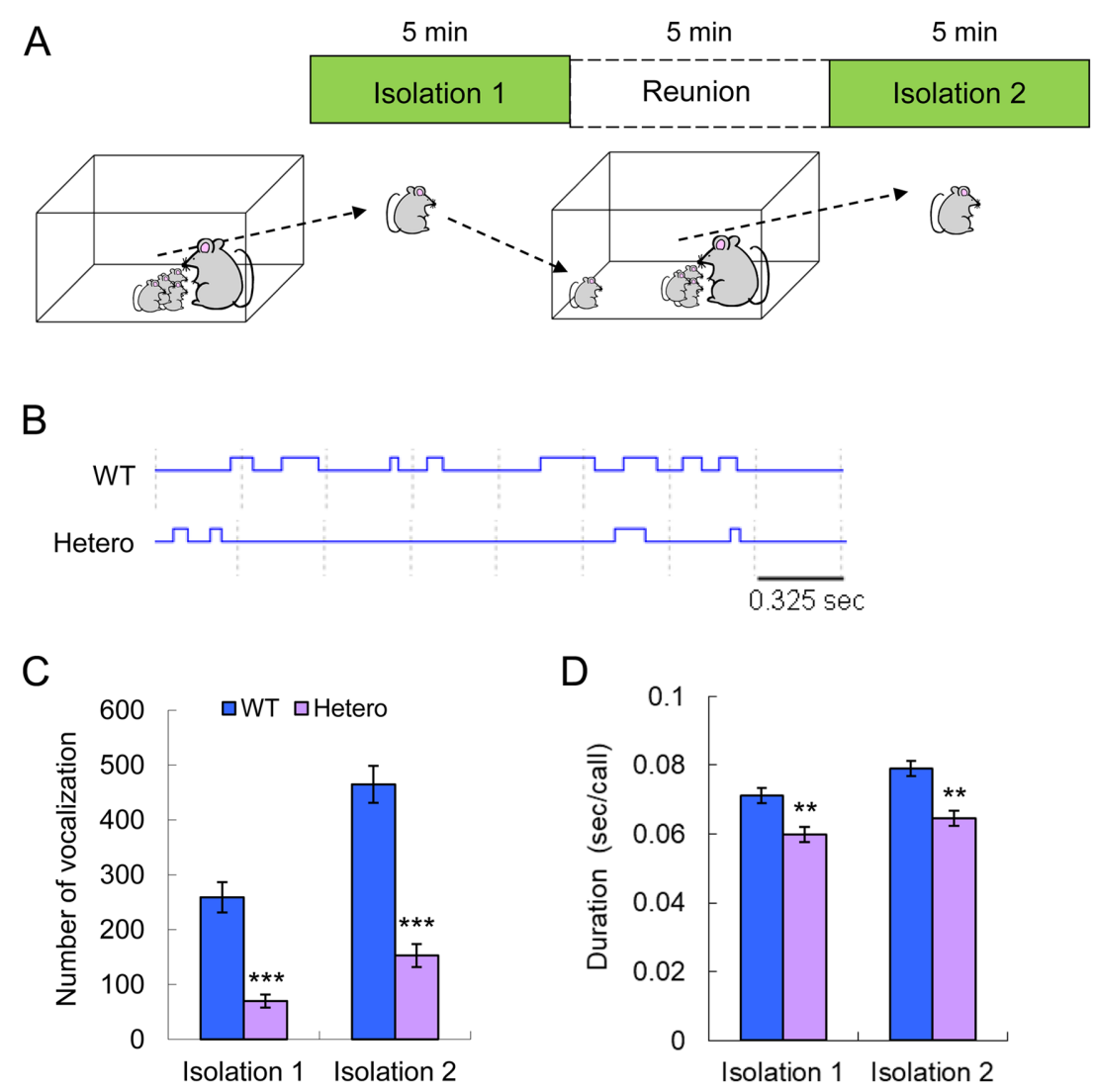

Fig. 3. Ultrasound vocalization (USV). Experimental setup for the USV test (A). Representative pattern of USVs in wild types (WT) and heterozygous offspring (B). The vertical axis represents On/Off of 50-kHz USVs. Number of vocalizations of WT and heterozygotes in five minutes $(\mathrm{C})$. Average duration of each vocalization for WT and heterozygotes (D) (WT offspring: $\mathrm{n}=44$, heterozygote offspring: $\mathrm{n}=39, * * P<0.01$ ).
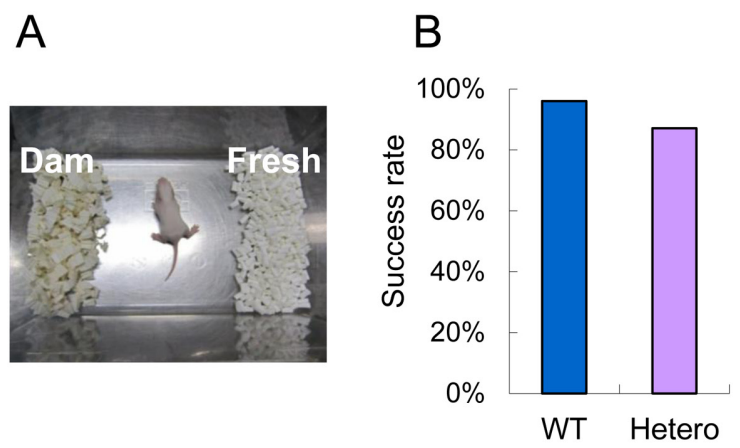
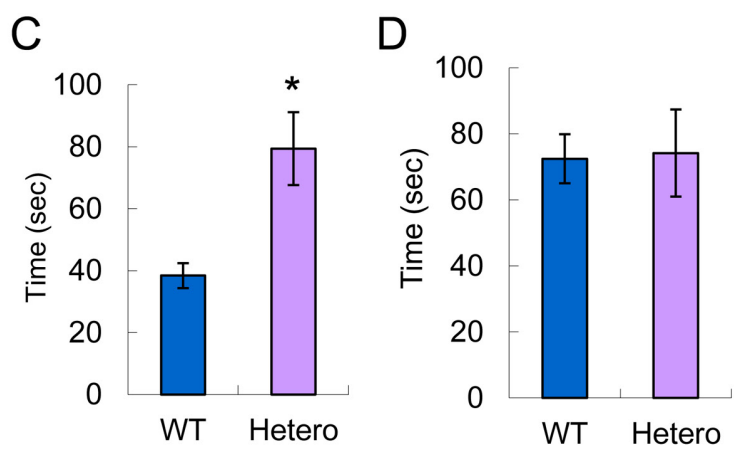

Fig. 4. Olfactory preference test. Experimental setup of the olfactory preference test (A). A sample of bedding used by the dam and a sample of new bedding were laid at either end of the cage $(8.5 \times 8 \times 13 \mathrm{~cm})$. A ten-day old pup was placed at the center of the cage and the time taken to touch the wall of the dam's bedding with the nose was recorded. No significant difference was found in the pups' success rate in reaching the dam's bedding within $300 \mathrm{~s}$ $(P=0.37)(B)$. Time taken to touch the wall of the dam's bedding with the nose (C) (wild types (WT) offspring: $\mathrm{n}=25$, heterozygote offspring: $\left.\mathrm{n}=31,{ }^{*} P<0.05\right)$. Time taken to find a hidden piece of chocolate (D).

been well studied. In mice, oxytocin receptor knockout dams show parenting failure. Decreased retrieval behavior and crouching has also been reported [37]. Even in nulliparous female rats, administering oxytocin into the cerebral ventricle induces parenting behavior [26]. Cacnala mutant mice are known to have synaptic release impairment at hippocampal glutamatergic synapses, which causes deficits in spatial learning and recognition memory $[18,22]$. The hippocampus, a site of $\mathrm{Ca}_{\mathrm{v}} 2.1$ channel expression, is known to have oxytocin projections [35]. It is reported that rodent mothers display spatial memory and hippocampal plasticity improve- 
ments in association with reproduction $[2,10]$, suggesting that rodents with Cacnala mutations will not show post-delivery improvement in hippocampal plasticity.

Mutant mice with selective deletion of the $\mathrm{P} / \mathrm{Q}$ channel $\alpha$ subunit gene Cacnala exhibit compensated alternation of N-type and T-type channels function [4, 28, 29, 34]. Calcium channel-mediated neurotransmitter release influences the degree of synaptic synchronicity $[4,11]$. These findings suggest that not only oxytocin, but also other mothering-related neurotransmitters, may be affected. Such defects may hinder the neurobiological network of maternal behavior.

In addition to maternal behavior abnormalities in heterozygous GRY dams, impaired attachment behaviors in offspring were also found. When separated from a WT dam, heterozygous offspring had significantly fewer USVs, which were of shorter duration, than WT offspring. In mice, offspring with oxytocin receptor knockout exhibited reduced USVs [37]. Fewer USVs in offspring to call dam in response to isolation is one of the major phenotypes of animal models for autism. $C A C$ $N A 1 A$ haploinsufficiency in humans causes autism [9]. After considereing all these evidences, we can infer that fewer USVs in heterozygous GRY offspring may be a partial indicator of autism. In this study, we did not conduct behavioral tests to clarify the autistic behaviors in GRY rats. Several behavioral tests for social interaction, cognitive function, and anxiety could provide an answer to the query in future studies.

Impaired mother-child attachment behaviors weaken their bond. Research on human postpartum depression reported that depressed mothers touched their children less frequently and in a less affectionate manner including rough pulling and poking $[13,14]$. When the mothers act in such negative way, it may affect the development of offspring attachment $[1,44]$. Irritated, hostile, or less engaged behaviors from the mother may negatively impact the child's attachment system $[14,20]$. Less interaction with the offspring involves a lower positive reinforcement of the child's behavior, which may later lead to negative behaviors in children. Parenting and offspring attachment have a mutually dependent relationship; thus, if either fails to return, a negative circuit in parent-offspring relationship may prevail. Without the reward of parenting, it may hinder the motivational system.

The present study had one limitation; the serum and brain hormone levels were not measured. Hormones such as oxytocin, vasopressin, dopamine, prolactin, estrogen, and progesterone are potential candidates for poor attachment behavior in GRY rats. Further studies, including hormone level evaluations, functional alternations of synaptic transmitter release, and neural networks, are needed to clarify the underlying mechanisms. In our society, the number of child abuse cases continues to increase, and the causes lie on undesirable pregnancies, vulnerability to stress, and important psychiatric disorders of the mothers; $9-10 \%$ of abusive parents have neuropsychiatric disorders [1]. Understanding the neurobiological processes underlying child abuse in attachment behavior may help us identify more effective therapeutic and preventive strategies.

\section{Acknowledgments}

We are thankful to the National Bio Resource Project for the Rat in Japan (http://www.anim.med.kyoto-u.ac.jp/ $\mathrm{NBR} /$ ) for providing the rat strains.

\section{References}

1. Adshead, G. 2015. Parenting and personality disorder: clinical and child protection implications. BJPsych Adv. 21: 15-22. [CrossRef]

2. Bales, K.L. 2017. Parenting in Animals. Curr. Opin. Psychol. 15: 93-98. [Medline] [CrossRef]

3. Batchelder, P., Lynch, C.B. and Schneider, J.E. 1982. The effects of age and experience on strain differences for nesting behavior in Mus musculus. Behav. Genet. 12: 149-159. [Medline] [CrossRef]

4. Bomben, V.C., Aiba, I., Qian, J., Mark, M.D., Herlitze, S. and Noebels, J.L. 2016. Isolated P/Q calcium channel deletion in layer VI corticothalamic neurons generates absence epilepsy. J. Neurosci. 36: 405-418. [Medline] [CrossRef]

5. Brown, J.R., Ye, H., Bronson, R.T., Dikkes, P. and Greenberg, M.E. 1996. A defect in nurturing in mice lacking the immediate early gene fosB. Cell 86: 297-309. [Medline] [CrossRef]

6. Bulloch, K., Hamburger, R.N. and Loy, R. 1982. Nest-building behavior in two cerebellar mutant mice: staggerer and weaver. Behav. Neural Biol. 36: 94-97. [Medline] [CrossRef]

7. Burne, T.H., O'Loan, J., Splatt, K., Alexander, S., McGrath, J.J. and Eyles, D.W. 2011. Developmental vitamin D (DVD) deficiency alters pup-retrieval but not isolation-induced pup ultrasonic vocalizations in the rat. Physiol. Behav. 102: 201204. [Medline] [CrossRef]

8. Curley, J.P., Jensen, C.L., Franks, B. and Champagne, F.A. 2012. Variation in maternal and anxiety-like behavior associated with discrete patterns of oxytocin and vasopressin 1a receptor density in the lateral septum. Horm. Behav. 61: 454461. [Medline] [CrossRef]

9. Damaj, L., Lupien-Meilleur, A., Lortie, A., Riou, É., Ospina, L.H., Gagnon, L., Vanasse, C. and Rossignol, E. 2015. CACNA1A haploinsufficiency causes cognitive impairment, autism and epileptic encephalopathy with mild cerebellar symptoms. Eur. J. Hum. Genet. 23: 1505-1512. [Medline] [CrossRef]

10. D’Cunha, T.M., King, S.J., Fleming, A.S. and Lévy, F. 2011. Oxytocin receptors in the nucleus accumbens shell are involved in the consolidation of maternal memory in postpartum rats. Horm. Behav. 59: 14-21. [Medline] [CrossRef]

11. Depetris, R.S., Nudler, S.I., Uchitel, O.D. and Urbano, F.J. 2008. Altered synaptic synchrony in motor nerve terminals lacking P/Q-calcium channels. Synapse 62: 466-471. [Medline] [CrossRef]

12. Dolphin, A.C. 2016. Voltage-gated calcium channels and their auxiliary subunits: physiology and pathophysiology and phar- 
macology. J. Physiol. 594: 5369-5390. [Medline] [CrossRef]

13. Ferber, S.G., Feldman, R. and Makhoul, I.R. 2008. The development of maternal touch across the first year of life. Early Hum. Dev. 84: 363-370. [Medline] [CrossRef]

14. Field, T. 2010. Postpartum depression effects on early interactions, parenting, and safety practices: a review. Infant Behav. Dev. 33: 1-6. [Medline] [CrossRef]

15. Hille, B. 2001. Ion channels of excitable membrane, 3rd edition. Sinauer Associates, Inc. pp. 95-129.

16. Hu, B., Guo, D. and Wang, Q. 2015. Control of absence seizures induced by the pathways connected to SRN in corticothalamic system. Cogn Neurodyn 9: 279-289. [Medline] [CrossRef]

17. Leckman, J.F., and Herman, A.E. 2002. Maternal behavior and developmental psychopathology. Biol. Psychiatry 51: 27-43. [Medline] [CrossRef]

18. Li, J., You, Y., Yue, W., Jia, M., Yu, H., Lu, T., Wu, Z., Ruan, Y., Wang, L. and Zhang, D. 2015. Genetic Evidence for Possible Involvement of the Calcium Channel Gene CACNA1A in Autism Pathogenesis in Chinese Han Population. PLoS One 10: e0142887. [Medline] [CrossRef]

19. Lijam, N., Paylor, R., McDonald, M.P., Crawley, J.N., Deng, C.X., Herrup, K., Stevens, K.E., Maccaferri, G., McBain, C.J., Sussman, D.J. and Wynshaw-Boris, A. 1997. Social interaction and sensorimotor gating abnormalities in mice lacking Dv11. Cell 90: 895-905. [Medline] [CrossRef]

20. Lovejoy, M.C., Graczyk, P.A., O'Hare, E. and Neuman, G. 2000. Maternal depression and parenting behavior: a metaanalytic review. Clin. Psychol. Rev. 20: 561-592. [Medline] [CrossRef]

21. Luo, A.H., Cannon, E.H., Wekesa, K.S., Lyman, R.F., Vandenbergh, J.G. and Anholt, R.R. 2002. Impaired olfactory behavior in mice deficient in the alpha subunit of $\mathrm{G}(\mathrm{o})$. Brain Res. 941: 62-71. [Medline] [CrossRef]

22. Mallmann, R.T., Elgueta, C., Sleman, F., Castonguay, J., Wilmes, T., van den Maagdenberg, A. and Klugbauer, N. 2013. Ablation of $\mathrm{Ca}(\mathrm{V}) 2.1$ voltage-gated $\mathrm{Ca}^{2+}$ channels in mouse forebrain generates multiple cognitive impairments. PLoS One 8: e78598. [Medline] [CrossRef]

23. Maselli, R.A., Wan, J., Dunne, V., Graves, M., Baloh, R.W., Wollmann, R.L. and Jen, J. 2003. Presynaptic failure of neuromuscular transmission and synaptic remodeling in EA2. Neurology 61: 1743-1748. [Medline] [CrossRef]

24. Moos, F., Poulain, D.A., Rodriguez, F., Guerné, Y., Vincent, J.D. and Richard, P. 1989. Release of oxytocin within the supraoptic nucleus during the milk ejection reflex in rats. Exp. Brain Res. 76: 593-602. [Medline] [CrossRef]

25. Numan, M., and Sheehan, T.P. 1997. Neuroanatomical circuitry for mammalian maternal behavior. Ann. N. Y. Acad. Sci. 807: 101-125. [Medline] [CrossRef]

26. Pedersen, C.A., and Prange, A.J. Jr. 1979. Induction of maternal behavior in virgin rats after intracerebroventricular administration of oxytocin. Proc. Natl. Acad. Sci. USA 76: 6661-6665. [Medline] [CrossRef]

27. Pietrobon, D. 2010. CaV2.1 channelopathies. Pflugers Arch. 460: 375-393. [Medline] [CrossRef]

28. Qian, J., and Noebels, J.L. 2000. Presynaptic $\mathrm{Ca}(2+)$ influx at a mouse central synapse with $\mathrm{Ca}(2+)$ channel subunit mutations. J. Neurosci. 20: 163-170. [Medline] [CrossRef]

29. Qian, J., and Noebels, J.L. 2001. Presynaptic Ca2+ channels and neurotransmitter release at the terminal of a mouse cortical neuron. J. Neurosci. 21: 3721-3728. [Medline] [CrossRef]

30. Rajakulendran, S., Kaski, D. and Hanna, M.G. 2012. Neuronal $\mathrm{P} / \mathrm{Q}$-type calcium channel dysfunction in inherited disorders of the CNS. Nat. Rev. Neurol. 8: 86-96. [Medline] [CrossRef] 31. Rocha, J.B., Soares, F.A. and De Mello, C.F. 2002. Influence of the test situation on pup retrieval behavior of normal and undernourished lactating rats. Braz. J. Med. Biol. Res. 35: 91-97. [Medline] [CrossRef]

32. Rossoni, E., Feng, J., Tirozzi, B., Brown, D., Leng, G. and Moos, F. 2008. Emergent synchronous bursting of oxytocin neuronal network. PLOS Comput. Biol. 4: e1000123. [Medline] [CrossRef]

33. Shair, H.N., Brunelli, S.A., Masmela, J.R., Boone, E. and Hofer, M.A. 2003. Social, thermal, and temporal influences on isolation-induced and maternally potentiated ultrasonic vocalizations of rat pups. Dev. Psychobiol. 42: 206-222. [Medline] [CrossRef]

34. Shi, R., Schroeder, G.M. and Nimarko, A.F. 2016. Dissecting the Role of $\mathrm{P} / \mathrm{Q}$-Type Calcium Channels in Corticothalamic Circuit Dysfunction and Absence Epilepsy. J. Neurosci. 36: 5677-5679. [Medline] [CrossRef]

35. Strathearn, L., Fonagy, P., Amico, J. and Montague, P.R. 2009. Adult attachment predicts maternal brain and oxytocin response to infant cues. Neuropsychopharmacology 34: 26552666. [Medline] [CrossRef]

36. Swain, J.E. 2008. Baby stimuli and the parent brain: functional neuroimaging of the neural substrates of parent-infant attachment. Psychiatry (Edgmont) 5: 28-36. [Medline]

37. Takayanagi, Y., Yoshida, M., Bielsky, I.F., Ross, H.E., Kawamata, M., Onaka, T., Yanagisawa, T., Kimura, T., Matzuk, M.M., Young, L.J. and Nishimori, K. 2005. Pervasive social deficits, but normal parturition, in oxytocin receptor-deficient mice. Proc. Natl. Acad. Sci. USA 102: 16096-16101. [Medline] [CrossRef]

38. Takeuchi, I.K., and Takeuchi, Y.K. 1991. Neuronal degeneration in the striatum of the groggy rat: a new mutant with a movement disorder. Experientia 47: 1215-1218. [Medline] [CrossRef]

39. Tanaka, K., Shirakawa, H., Okada, K., Konno, M., Nakagawa, T., Serikawa, T. and Kaneko, S. 2007. Increased Ca2+ channel currents in cerebellar Purkinje cells of the ataxic groggy rat. Neurosci. Lett. 426: 75-80. [Medline] [CrossRef]

40. Thomas, S.A., and Palmiter, R.D. 1997. Impaired maternal behavior in mice lacking norepinephrine and epinephrine. Cell 91: 583-592. [Medline] [CrossRef]

41. Tobin, V., Leng, G. and Ludwig, M. 2012. The involvement of actin, calcium channels and exocytosis proteins in somatodendritic oxytocin and vasopressin release. Front. Physiol. 3: 261. [Medline] [CrossRef]

42. Tokuda, S., Kuramoto, T., Tanaka, K., Kaneko, S., Takeuchi, I.K., Sasa, M. and Serikawa, T. 2007. The ataxic groggy rat has a missense mutation in the P/Q-type voltage-gated Ca2+ channel alpha1A subunit gene and exhibits absence seizures. Brain Res. 1133: 168-177. [Medline] [CrossRef]

43. Uematsu, A., Kikusui, T., Kihara, T., Harada, T., Kato, M., Nakano, K., Murakami, O., Koshida, N., Takeuchi, Y. and Mori, Y. 2007. Maternal approaches to pup ultrasonic vocalizations produced by a nanocrystalline silicon thermo-acoustic emitter. Brain Res. 1163: 91-99. [Medline] [CrossRef]

44. van IJzendoorn, M.H. 1995. Adult attachment representations, parental responsiveness, and infant attachment: a meta-analysis on the predictive validity of the Adult Attachment Interview. Psychol. Bull. 117: 387-403. [Medline] [CrossRef]

45. Wersinger, S.R., Ginns, E.I., O'Carroll, A.M., Lolait, S.J. and Young, W.S. 3rd. 2002. Vasopressin V1b receptor knockout reduces aggressive behavior in male mice. Mol. Psychiatry 7: 975-984. [Medline] [CrossRef] 